\title{
School Gardening Activities have Profound Potential in Influencing the Knowledge, Attitude, Self-efficacy and Frequency of Fruit and Vegetable Intake by Late Adolescents
}

Hussein Mukasa Kafeero ( $\nabla$ husseinmukasakafeero@gmail.com )

Islamic University in Uganda https://orcid.org/0000-0002-0247-8783

David Kavuma

Uganda Martyrs University Faculty of Sciences

Lillian Wampande Nantume

Uganda Martyrs University

Scovia Mbabazi

Uganda Martyrs University

Research article

Keywords: Attitude, Self-efficacy, Frequency, Knowledge, Late adolescents

Posted Date: August 31st, 2019

DOl: https://doi.org/10.21203/rs.2.13719/v1

License: (c) (1) This work is licensed under a Creative Commons Attribution 4.0 International License.

Read Full License 


\section{Abstract}

Back ground The dietary intake of fruits and vegetables by adolescents is influenced by self-efficacy, attitude and knowledge.This study was designed to understand the role of school gardens in influencing the frequency, attitudes, knowledge and self-efficacy of late in-school adolescents on their dietary intake of fruits and vegetables.Methods The study followed a cross-sectional study design employing quantitative research methods. The target population comprised of late adolescents 18-25 years attending the two-selected secondary school; one with gardening activities and another not. Selfadministered structured questionnaire was used to collect data. Quantitative data was analyzed by t-test , Mann Whitney U test, Pearson Rank Correlation and odds ratio.Results Generally, there were low fruit (8 \& 9 ) and vegetable ( $6 \& 7$ ) servings per week among the unexposed and the exposed groups respectively as compared to the USDA recommendation (14 and 11) servings per week for fruits and vegetables respectively. However, students exposed to gardening had slightly higher scores of fruits and vegetable frequency as compared to those not exposed $(O R=1.0370)$. Students believed they consumed more fruits than vegetables with the exposed group consuming more fruits $(p<0.0001)$ and vegetables $(p<0.0001)$ than the control group. The students knew more nutritional value for fruit intake than for vegetable intake with the exposed group having higher knowledge scores than the control $(\mathrm{OR}=1.32)$. The students in the exposed group were more confident in consuming fruits and vegetables rather than a snack $(p=0.008)$, ice cream $(p=0.004)$, three times a day $(p<0.0001)$ compared to the control group.Conclusion Overall, there was low fruit and vegetable intake by the study subjects. However, fruits were consumed more than the vegetables with the exposed group posting slightly higher weekly intake of fruits and vegetables than the control group. The students knew the nutritional value of fruits and vegetables attaching more importance on the fruits than vegetables with exposed group having better knowledge than the control. Although students in both groups were confident in consuming fruits and vegetables, the exposed group was more confident than the unexposed.

\section{Background}

Many nutrition related health interventions have focused on children less than five years (Kimokoti \& Hamer 2008, Faruque et al. 2008, Gulati 2010), pregnant women (Mecacci et al. 2015) and HIV/AIDS (Byron et al., 2006) with less focus on late adolescents. This stage is a complex developmental stage and the health eating interventions designed have to be acceptable by the target group (Christian et al., 2012). Among the school going adolescents, interventions designed and implemented at school are always accepted (Robinson-O'Brien R, Story M, Heim S; 2009, McAleese JD, Rankin LL (2007) and they provide an opportunity to reduce inequalities in nutrition health for all school going adolescent (Robinson-O'Brien R, Story $M$, Heim S; 2009). Of the many interventions designed to improve the attitude, efficacy, knowledge and frequency of the dietary intake of fruits and vegetables by adolescents, school gardening programs are promising (Robinson-O'Brien R, Story M, Heim S; 2009).

Many authors define adolescent stage differently. It is a developmental stage that manifests with rapid physiological, psychosocial, and physical changes (Steinberg, 2014). It is a stage marked with puberty 
onset spanning the age between 10-18 years (Steinberg, 2014). The Society for Adolescent Medicine (SAM) highlights the adolescent stage as the growth period between 10 to 25 years (SAM 1995). The Center for Disease Control uses academic grades between 9-12, rather than age (CDC, 2015) to define adolescents. The World Health Organization (WHO, 2015) defines "adolescents" as individuals between 10 and 19 years. This lack of consistence in the inclusion criterion challenges studies involving adolescents and the subsequent design of health interventions.

Adolescents have been divided into early, middle and late sub-classes. Early adolescence is 10 to 13 years, middle adolescence 14 to 16 years, and late adolescence 17 to 21 years (Nielsen et al. 2014). A closely related classification has been given by Steinberg (2002) with early adolescents being 10 to 13 years, middle 14 to 18 years and late 19 to 22years. The different stages of adolescents are associated with variations in physiological, physical and psychosocial dynamics calling for different health promotion interventions at each stage (Nielsen et al. 2014).

The recommended fruit and vegetable intake for our participants according to United States Department of Agriculture (USDA) is 14 and 11 intakes per week respectively (USDA, 2015). A study by Kim et.al., (2014) reported low intake of fruits by adolescents. However, Harrington EM, (2016) reported higher serving per week in the range of 14-21 for fruits and 21-28 for vegetables. These contradictions in the available literature warrant more investigations in this subject.

Kim et al., (2014) and Nielsen et al., (2014) reported a steady decline in the intake of fruits and vegetables through each stage of adolescence. The decline ranges from 0.7 servings per day from early (11-14 years) to mid (15-18 years) adolescence followed by another decrease of 0.6 servings per day from mid to late adolescence $(19+$ years old). However, fruits and vegetables availability strongly influences the dynamics of the frequency of adolescent's fruit and vegetable intake (Di Noia \& Byrd-Bredbenner, 2013, Arcan et al., 2007).

Students engaged in gardening activities have positive attitude related to fruit and vegetable consumption compared to the unexposed group (Bere E \& Klepp K-I., 2005). Exposure to a wider range of vegetables and fruits through gardening activities builds a positive attitude towards fruits and vegetable intake (Kristjansdottir AG et al., 2006). Involvement in the production and preparation of food can influence the attitude of the students towards intake of fruits and vegetables (Robinson-O'Brien R, et al., 2009). More importantly, when new food is exposed to the student several times it becomes easy to accept it (Thompson et al., 2007). Kothe et al., (2012). Generally adolescents have stronger attraction to fruits than vegetables because of their color and scent (Davis JN \& Spaniol MR, 2015, Davis JN \& Spaniol MR, 2015).

Self-efficacy is one of the key indicators of fruits and vegetable intake among the adolescents as highlighted in the studies by Thompson, Bachman, Baranowski, and Cullen, 2007; 2004; Pedersen et al. 2015 and Fitzgerald et al. 2013. Self-efficacy and self-confidence in intake of fruits is influenced by the adolescent involvement in gardening activities (Pedersen et al., 2015, Davis JN \& Spaniol MR, 2015, Oxenham, E.; King, 2010) School gardens, where present have increased the confidence of adolescents in 
the eating of fruits and vegetables. The choice of food and dietary habits are shaped early in life (Neumark-Sztainer et al. 2011) and hence, hands on activities during adolescence will largely contribute to the confidence later in life to take fruits and vegetables. Heneman et al. (2008) established that incorporating agriculture into schools links school, family and community activities.

Exposure to a wider range of vegetables and fruits through gardening activities has been observed to increase students self-confidence/self-efficacy (Cockroft JE et al.,2005) towards vegetable and fruit consumption. However, Morgan PJ et al.,( 2010), Jaenke et al., (2012) and Kothe et al. (2012) did not find a relationship between enhanced self-efficacy and gardening activities. Thus this lack of consistence in the available literature calls for more studies to verify this hypothesis.

Limited knowledge by adolescents regarding the nutritional value of fruits and vegetables curtails their intake. Krolner et al., 2011 reported that adolescents are not aware of long term benefits of fruit and vegetable intake rather they are interested in the short term benefits. Ying et al., 2009 established that low intake of fruits and vegetables is due to gross lack of awareness, knowledge and motivation among adolescents regarding health eating. In a related study, by Sylvetsky et al., (2013), youth believed that they are not vulnerable to disease so, not worried about health eating

Servings and preparation of fruits have been observed to increase adolescent's knowledge towards nutritional potential of the fruits and vegetables. Arcan et al., 2007 established that that serving fruits and vegetables during meals improves the adolescent's knowledge as regards nutritional value of fruits and consequently improves the intake of fruits and vegetables. Other studies have reported that girls are more knowledgeable than boys as regards the nutritional value of fruits and vegetables due to their involvement in their preparations (Stok et al., 2014, Oxenham EK et al., 2010, Ganann, R et al., 2014). In a longitudinal study by Molaison-Fontenot, Connell, Stuff, Yadrick \& Bogle, 2005 on intake of fruits and vegetables by the low income black American students, girls overall had better knowledge about the intake of fruits and vegetable than the boys because they are involved in their preparation

Empowerment of adolescents through gardening activities improves their skills and knowledge to grow fruits and vegetables which is a key motivator of change in nutritional behavior of adolescents. Morris \& Zidenberg-Cherr (2002), Koch et al. (2006) and Finkelstein \& Strombotne (2010) reported a strong correlation between having a direct experience with growing food and the children's understanding of food as well as its relationship to health.

A systematic review by Davis JN, Spaniol MR (2015), outlined the potential of student's hands on during garden activities in enhancing their knowledge towards health eating. The review highlighted an increase in the learner's knowledge regarding fruits and vegetables when the school garden is part of the nutrition education program. This argument is consistent with findings from two interventional studies by Somerset \& Markwell (2009). These assessed the impact of a school-based food garden on improving knowledge and skills to increased vegetables and fruit intake among Latino youth which revealed a strong correlation. 
Contento et al. (2006) studied 115 second grade students and their knowledge, preference, and consumption of fruits and vegetables as part of a classroom and classroom/gardening program. The results indicated that participants who received nutrition education alone, as well as nutrition education and gardening education had increased nutrition knowledge and fruit/vegetable taste ratings than the control group.

This study was therefore aimed at illuminating on the role of school gardens in promoting health nutrition among late adolescents by comparing the efficacy, attitude and knowledge towards fruits and vegetable intake between the exposed and unexposed groups to gardening activities at school. The study further highlighted the differences in the weekly intake of fruits and vegetables by the adolescents in the two groups to establish the state of fruit and vegetable intake among the adolescents in the two groups relative to the recommendations from the United states Department of agriculture and the World Health Organization weekly recommendations.

\section{Methods}

\section{Research Design}

This was a descriptive cross sectional research study employing quantitative methods of data collection and analysis.

\section{Study area}

The study was carried out from two schools; one with students actively involved in school gardening activities while another not. The school with students participating in school garden is located in Bombo central ward, Bombo town council sub-county, Katikamu South constituency in Luwero district.

The school with no school garden is located in the central division of Kampala, Kampala central constituency. The two setting were selected purposely because they are quite similar since they are both constrained by space, are universal day public schools with about the same enrollment. The students attending both schools come from low social economic status families

The survey used 355 high school students in the selected schools with and without school gardens aged between 18-22 years.

Inclusion criteria

Advanced level students in the two schools aged 18-22 years.

\section{Exclusion criteria}

Advanced level students in the two schools below 18 years and all ordinary level students and all ordinary level students regardless of the age 
Sampling procedures

Sample size

For the quantitative arm, the sample size, $n$, was calculated using the formula described by Cochran, $\mathrm{W}$. G. (Cochran, 1977). A proportion of $50 \%$ fruit and vegetable intake was used

Sampling Technique:

Purpose sampling was done for the selection of the two schools used in the study because of the similarity of the two schools in terms of social economic status of the parent, both are constrained by space and both are under the universal secondary education. The survey used 355 high school students in the selected schools with and without school gardens that were selected randomly by stratified sampling using the class lists as the sampling frames. A random sample of 170 and 185 respondents was drawn from the school with and without gardening activities respectively.

Design of instruments for data collection

Self-administered questionnaire with four sections to collect data were used. All the questions were obtained from validated questions used in food intake related questionnaires.

To gather data on the level of knowledge students have over the role of fruits and vegetables in a health, the fruit and vegetable intake frequency questionnaire (FVKQ) was adopted. This was modified and adopted from Matt et al., 2006 with minor modifications to suit the local fruits

The data on weekly intake of vegetables was collected by using the section of the questionnaire called the food and vegetable frequency questionnaire (FVFQ). The questions in this section were adopted from Rockett et al., 1995.

To assess students' attitudes towards fruit and vegetable consumption, the Eating and activity in Teens and Young adults developed by Neumark-Sztainer and colleagues, 2012 was adopted with minor changes. This questionnaire was called the fruit and vegetable attitude questionnaire (FVAQ)

The previously validated tool for self-efficacy related to fruits and vegetable consumption for adolescents aged 11-19 by Hagler et al., 2005, Bandura, 2006, and Sharma et al., 2014 was adopted after it was optimized to meet the local fruits and vegetables. This was called the fruit and vegetable efficacy questionnaire (FVEQ). The survey on the assessment school gardens in influencing fruit and vegetable intake efficacy was adopted from the scale developed by Sunette M, 2017. This was designated the influence of gardening activities on fruit/vegetable intake at school questionnaire (FVSQ)

For internal reliability of the questions within each questionnaire were tested for internal reliability using Cronbach's alpha. All sections of the questionnaire gave values of $a>0.7$ which signifies a good internal reliability. 


\section{Results}

\section{Data analysis}

The results were presented in terms of means \pm standard deviations. The mean scores for all the variables in the exposed and unexposed groups provided a variable for analysis. Differences in means were assessed by t-tests/Mann Whitney U Tests for parametric and non-parametric variable respectively depending on the degree of normality of the data. The odds ratio for the association of the study variable with the intake of fruits and vegetables intake was computed. To establish the conditions that would influence student's efficacy related to intake of fruits and vegetables attributable to gardening activities, the questions were correlated on gardening activities with self-efficacy questions using Spearman Rank correlation. All analyses were done at $95 \%$ significance level and $p<0.05$ was considered significant.

The frequency of fruits taken in on a weekly basis was determined by pooling the daily and weekly intakes. For example, if the fruit or vegetable was eaten twice for every two weeks, then the conversion was a half intake of fruit per week. If it was consumed 3times a day, then it was consumed 21 times a week. The total fruit consumption for every week was calculated by adding all the scores for questions from the questionnaire on FVFQ. The same procedure was used for the vegetables consumed on a weekly basis by summing up all the codes for questions on vegetable intake in the FVFQ.

For any unanswered question, the response was assumed to be zero intake per week. This is the common procedure in food frequency questionnaire which implies that if someone does not answer the question, it means he/she does not eat that food item (USDA, 2015).

The scores on the student's belief and attitude related to sufficiency/insufficiency in the intake of fruits and vegetables were determined on the Likert scale: Never (0), almost never (1), sometimes (2) and all the time (3). These were used for analysis.

The responses from the questions on the Fruit and Vegetable Knowledge Questionnaire (FVKQ) were used to compare the underlying reasons why students would consume the fruits and vegetable. They were asked to give their level of agreement on the Likert scale items of the questionnaire emphasizing the value of dietary inclusion of fruits and vegetables. The scores were computed and the average score calculated which was used for statistical analysis.

Self-efficacy for eating fruits was assessed using FVEQ and FVSQ questionnaires. All questions were coded as follows: definitely I can=5, I think I can=4, maybe I can=3, not sure I can=2 and don't think I can $=1$, and the answers for each question were added together and divided by the number of questions to obtain a Self-Efficacy Mean Score.

The influence of gardening activities attributable to fruit consumption was assessed by the FVSQ. All the questions were coded as follows: Very much $=3$, sometimes $=2$, a little bit $=1$ and not at all= 0 . The answers for each question were added divided by the number of questions to obtain the Gardening Attributable Mean Score (GAMS). 
The differences in means of GAMS score between the two groups of students with and without school gardens were tested for statistical significance by using Mann Whitney U test statistic. To establish the conditions that would influence student's efficacy related to intake of fruits and vegetables attributable to gardening activities, the questions were correlated on gardening activities with self-efficacy questions using Spearman Rank correlation.

All the items of the questionnaire were tested for internal validity using Cronbach's alpha giving a value of $a \geq 0.72$ showing a good internal validity.

\subsection{Demographics}

The study had more males (56.3\%) than females (43.7). The he girls were generally young than the boys in both the exposed and the unexposed schools to gardening activities. The mean ages of the girls and boys in the school exposed to gardening activities were $19.10 \pm 1.4$ and $19.2 \pm 2.86$ respectively while those for students in the unexposed school were $18.62 \pm 1.21$ and $19.11 \pm 1.29$ respectively (Table.1)

Fruit and vegetable intake per week

Low fruit $(8.2 \pm 8.6 \& 8.8 \pm 8.5)$ and vegetable $(6.26 \pm \& 6.65 \pm 6.6)$ servings per week among the unexposed and the exposed groups respectively (Table.2) as compared to the USDA recommendation (14 and 11) servings per week for fruits and vegetables respectively was found.

However, weekly fruit intake was higher $(\mathbf{8 . 5} \pm \mathbf{8 . 6})$ than vegetable intake $(\mathbf{6 . 5} \pm \mathbf{6 . 1 4})$ for both students in the exposed school to gardening activities and those in the unexposed school (Table.2).

When the mean difference in weekly intake of fruits and vegetables was analyzed for statistical significance; $\mathrm{OR}=1.0370, \mathrm{p}=0.9607$ ( $95 \% \mathrm{Cl} ; 0.2267$ to 4.1018) (Table.3). Although gardening was associated with increased weekly intake of fruits and vegetables $(O R>1)$, the difference was not statistically significant $(p>0.05)$.

Attitudes towards fruit and vegetable intake

In this survey, the differences in the attitudes by students related to the intake of fruits and vegetables in their diet were assessed by using the fruit and vegetable attitude questionnaire (FVAQ). The weekly fruit and vegetable intake rate was determined by getting the scores of all the students and in the exposed/unexposed school to gardening activity for that item question. Then the mean score established by dividing by the total number of students.

When asked about their attitude on fruit and vegetable intake, students in both settings had positive attitude (>2.0) which was the mean score on the Likert scale (0-4) with the exposed group having a slightly higher scores $(2.25 \pm 0.9)$ than the unexposed group (2.43 \pm 0.9$)$ (Table.4). 
When analyzed using the Mann Whitney $U$ test, the exposed group had significantly higher positive attitude towards the good taste of fruits than the control $(p=0.01108)$.

Intake of fruits and vegetables in both groups was least influenced by the peers (20\% and $22.5 \%)$ in the exposed and unexposed students respectively. However, the attitude of the students towards intake of fruits in the exposed and unexposed groups greatly influenced by the good taste of the fruits $(92.5 \%$ \& $82.5 \%)$ and vegetables $(87.5 \% \& 80.0 \%)$ respectively. The overall mean frequency scores (\%) were higher in the exposed $(60.6 \%)$ than the control (56.3\%) (Table.5). On their attitude whether they take in sufficient/insufficient fruits and vegetables, the students who consumed fruits and vegetables all the time were more in the exposed group $(26.5 \% \& 11.88 \%)$ respectively compared to the control group $(4.7 \%$ \& $3.65 \%$ ) respectively (figures $1 \& 2$ ).

When the differences in the scores on the students attitude whether they take in sufficient vegetables were analyzed, the students exposed to gardening activities had significantly higher positive attitude and beliefs in themselves than the control group; $p<0.0001,(95 \% \mathrm{Cl}=0.325$ to 0.606$)$ as shown in table 6

However, When the differences in the scores on the students attitude whether they take in sufficient fruits were analyzed, the students exposed to gardening activities had significantly higher positive attitude and beliefs in themselves than the control; $p<0.001,(95 \& \mathrm{Cl}=-0.8122$ to -0.5518$)$ as shown in tables 7 .

Student's knowledge on fruits and vegetables

The total scores and the percentage of the total scores of the students on the questions soliciting for their knowledge as regards fruits and vegetable intake were compared (Table.8). The exposed students had higher total scores for fruits and vegetables intake of $10.4(87.7 \%)$ and $10.1(84.4 \%)$ respectively compared to the control group with total scores of $7.3(60.8 \%)$ and $6.1(50.8 \%)$.

The difference in mean total scores on the student's knowledge regarding the nutritional value of fruits and vegetables were analyzed for statistical significance (Table. 9). The students exposed to gardening activities had better knowledge than the unexposed group as to why fruits are important in the diet; $\mathrm{OR}=1.06, \mathrm{p}=0.876(95 \% \mathrm{Cl} ; 1.44$ to -1.32$)$

Students the exposed to gardening activities were 1.06 times more knowledgeable as to why they needed fruits in their diet compared to control group. However, the difference in knowledge was not statistically significant $(p<0.05)$. Associations showing self -efficacy related to gardening

In order to establish the conditions that would influence student's efficacy related to intake of fruits and vegetables attributable to gardening activities, we correlated questions on gardening activities with selfefficacy questions using Spearman Rank correlation (Table. 11).

Students were more confident that they could eat fruits and vegetables rather than a chip as a snack because they grow fruits and vegetables at school $(p=0.04776)$, are involved in gardening $(p=0.034084)$ and their desired fruits are present in the school garden $(P=0.01785)$. 
Similarly, students were more confident that they could eat fruits and vegetables 3 times a day because they grow fruits and vegetables at school $(p=0.004399)$, are involved in gardening $(p=0.008314)$ and their desired fruits are present in the school garden $(p=0.005123)$. Students were more confident that they could eat fruits and vegetables be every dinner cause they grow fruits and vegetables at school $(p=0.005223)$ and their desired fruits are present in the school garden $(p=0.026445)$.

\section{Discussion}

This study compared the frequency, attitudes of students, knowledge and self-efficacy related to dietary intake of fruits and vegetables in two schools. One school had the students exposed to gardening and another did not. This chapter gives a detailed discussion of the findings of the study with reference from the established studies in literature. Each of the study objectives will be discussed separately in this section.

Overall, from the survey questionnaire results, adolescents expressed low intake of fruits and vegetables in both settings although students exposed to gardening activities had higher weekly intake of both fruits and vegetabes. These findings have been reported elsewhere by Kim et.al., (2014) and Kimmons et al., (2009) which reported $9 \& 7$ servings of fruits and vegetables per week respectively. However, the findings contradicted a recent study by; Harrington EM, 2016 which reported higher serving per week in the range of 14-21 for fruits and 21-28 for vegetables and, a study by Behjat Shokrvash et al.,2013 which reported a serving of $5 \& 3$ daily servings of fruits and vegetables respectively.

However, the survey by Harrington EM, (2016) and Behjat Shokrvash et al.,(2013) used young adolescents with average age of 12 years. This discrepancy in the two studies could have biased the findings.

Inadequate supply is critical in meeting and or exceeding the weekly dietary intake of fruits and vegetables. Our participants did not meet or exceeded the USDA recommended intake of fruits and vegetables because of inadequate supply. In the survey where the late adolescents met the recommended intake, the schools provided fruits and vegetables as part of the school menu for lunch (Di Noia \& Byrd-Bredbenner, 2013).

Di Noia \& Byrd-Bredbenner, 2013 in his study on the influence of family support and home availability of fruits and vegetables to their dietary intake by grade 6 students in a Unites states Multi-cultural community reported that availability of fruits and vegetables is a critical determinant of adolescent fruit and vegetable intake frequency. 
Thus in the current study, the school that exposed students to gardening activities and served students with fruits and vegetables had higher weekly fruit and vegetable intake scores. This finding is not surprising as it was reported elsewhere by Arcan et al., 2007 who established that serving fruits and vegetables during meals enhances the adolescent's intake of fruits and vegetables.

These findings differ from other studies assessing dietary intakes of adolescents. Kimmons et al. (2009) found adolescents (aged 12-19 years) rarely met recommendations of some fruits and vegetables in a multi-cultural setting but meeting the requirements of others. The high intake of beans our survey is reflective of the participant's cultural diets, with beans being a significant part of African cultural diet.

Individual factors such as the rapid changes in physical growth and development that occur during different phases of adolescence may reduce the intake of fruits and vegetables. Larson et al., 2009, Kim et al., 2014, and Nielsen et al., 2014 reported a steady decline in the intake of fruits and vegetables through each stage of adolescence. The decline ranges from 0.7 servings per day from early (11-14 years) to mid (15-18 years) adolescence followed by another decrease of 0.6 servings per day from mid to late adolescence $(19+$ years old). Their findings are consistent with an earlier study which reported a decline in fruit and vegetable consumption from the onset of adolescence at a rate of 1.4 decline in intakes per day and it appear to progress through adulthood (Larson et al., 2007).

During adolescence, a sense of independence develops and frequently they make an irrational decision which affects their dietary intake of fruits and vegetables. Our study used late adolescents (18+ years) with tremendous decline in dietary intake of fruits and vegetables. The low intake of fruits and vegetables has also been explained by Ying et al., 2009 who reported gross lack of awareness, knowledge and motivation among adolescents regarding health eating. In a related study, by Sylvetsky et al., (2013), youth believed that they are not vulnerable to disease so, not worried about health eating. Consequently individual factors influence behavioral change as outlined in the social ecological model that underpins our study

In our study, students exposed to gardening had higher weekly vegetable intake than the control group. Parmer SM. et al., 2009 established that exposure to hands on gardening activities to grow fruits and vegetables generally are associated with their increased consumption. They found an increased fruit and vegetable consumption among Grade 2 students with a school garden intervention. However, their sample was mostly made up of boys. McAleese et al. (2007) also reported an increase in vegetable consumption among Grade 6 students after a school garden program, but used $24 \mathrm{~h}$ food recall workbooks completed by students lowering the potential of long term intake of fruits and vegetables, which would have biased the results. 
In a related study by Lineberger and Zajicek SE and Zaijicek (2000), an increased vegetable preference as a result of school garden intervention was highlighted. Arcan et al., 2007 also established that that serving fruits and vegetables during meals enhances the adolescent's intake of fruits and vegetables. Thus, gardening activities empower students by giving them skills to grow fruits and vegetables which is a key motivator of change in nutritional behavior of adolescents. However, the school garden program evaluated by Lineberger and Zajicek (2000) did not impact on intake or preferences for fruit, but had a positive impact on vegetable intake thus contradicting the findings of the current study. This is consistent with the study by (Jaenke et al., 2012) who reported no changes in frequency fruit and vegetable intake as a result of a school gardening programme (Jaenke et al., 2012).

Our study and the former study used different methods. The current study used food frequency questionnaires which have been adopted by many recent studies in evaluating attitude, frequency, knowledge and efficacy related to fruit and vegetable intake by school children (Sharma et al., 2014, Emily M, 2016, Neumark-Sztainer et al.,, 2012). The previous study used students' nutritional behaviors regarding fruit and vegetables evaluated through 24 -hour recall journals. These lower the potential of long term intake of fruits and vegetables. The methodological differences could have biased the findings.

Studies have reported self-efficacy as a valid determinant of fruit and intake by late adolescent (Pedersen et al. 2015 and Fitzgerald et al. 2013). In their case-control study, Pedersen et al., (2015) established that the interventional group in the schools which served fruits and vegetables as part of the school menu was more confident than the control group in the intake of fruits and vegetables.

In our study, students exposed to gardening activities had high self-efficacy scores related to intake of fruits and vegetables. They were more confident that they could eat fruits/vegetables rather than a snack, ice cream, 3 times a day and fruit/vegetable every breakfast as compared to the unexposed group.

According to the socio-ecological model, self regulation and Self-confidence influence behavioral change such as health promotion practice. For fruit and vegetable intake every dinner, 3 times a day and as snack rather than chips were correlated with gardening activities at school. These findings are consistent with earlier reports that highlighted the importance of self-efficacy in improved fruit and vegetable intake (Thompson, Bachman, Baranowski, and Cullen, 2007; Pedersen et al. 2015 and Fitzgerald et al. 2013).

However, many studies have reported contradictory findings. Keyte, J., et al., (2012) did not find an association between gardening at school and increased self efficacy towards the dietary intake of fruits and vegetables. However, the differences in the age of the learners and the setting could explain the 
differences in the results. The study by Keyte and co-workers used pre-adolescents but our study and Bere's study used adolescents as the study subjects.

Similarly, the study by Morgan PJ et al.,(2010) on the impact of nutrition education with and without a school garden on knowledge, vegetable intake and self-efficacy found no differences in fruit or vegetable intake. This was consistent with the studies by Jaenke et al., (2012) who reported no changes in fruit and vegetable intake as a result of a school gardening programme and Kothe et al. (2012), who examined the efficacy intervention on fruit and vegetable consumption but did not see behavior change related to fruit and vegetable consumption among students in schools with or without the school garden.

The discrepancy in these studies may be due to the young age of participants investigated (mid adolescents) but might also be due to the methodological differences. Morgan et al., (2010) used 24-hour recalls to measure fruit, vegetables or combined fruit and vegetables consumption,

Kothe et al. (2012) used a three day food diary while Jaenke et al., (2012) used teacher-child based. The teacher's willingness to teach the intervention and own beliefs in the importance of gardening could have introduced bias into these results. Most importantly however, the study by Morgan PJ et al., (2010) was conducted in was conducted in Australian regions, where fruit and vegetables can be grown all year round which are not universally true in our setting and elsewhere. In the current study, it was the opinion of the students as regards the intake of fruits and vegetables. This difference may then explain the discrepancy between their studies and our study.

Generally students had higher self- efficacy and higher towards intake of fruits than vegetables. This finding has been reported in previous studies. Adolescents are attracted to fruits because of their color, scent and (Davis JN \& Spaniol MR, 2015, Davis JN \& Spaniol MR, 2015). Fortunately, the color of the fruit has been reported to indicate nutrient richness. Specifically, red and orange fruits are rich in vitamin A and carotenes, which act as anti-oxidants (USDA. 2015).

When we compared the percentage of the total scores of the students on the questions soliciting for their knowledge as regards fruits and vegetable intake were compared, $87.7 \%$ and $84.4 \%$ of the students exposed to gardening knew the nutritional value of fruits and vegetables respectively. However, $60.8 \%$ and $50.8 \%$ of the unexposed students to gardening knew the value of fruits and vegetables in the diet.

Although the students exposed to gardening activities had better knowledge as to why fruits were important in the diet, the differences were not statistically significant. However, what has been very consistent by many researchers and systematic reviewers is that increased serving, preparation and handling of fruits and vegetables improves the adolescent's knowledge as regards the nutritional value of fruits and vegetables.

Studies by Arcan et al., 2017 established that that serving fruits and vegetables during meals improves the adolescent's knowledge as regards nutritional value of fruits and vegetables. Thus schools that 
include fruits as part of their school menu improve the student's knowledge on fruits and vegetables consistent with the results of the current study.

Handling fruits and vegetables is a key determinant of improved knowledge regarding their nutritional benefit. Oxenham EK et al., (2010) in his work on the role of school gardens as a strategy in increasing fruit and vegetable intake reported that girls are more knowledgeable than boys as regards the nutritional value of fruits and vegetables due to their involvement in their preparations. This has been reported elsewhere (Ganann, R et al., 2014, Molaison-Fontenot, Connell, Stuff, Yadrick \& Bogle, 2005) and is consistent with our findings.

Empowerment of adolescents through gardening activities improves their skills and knowledge to grow fruits and vegetables which is a key motivator of change in nutritional behavior of adolescents.

Finkelstein \& Strombotne (2010) reported a strong correlation between having a direct experience with growing food and the children's understanding of food as well as its relationship to health. This has been explained elsewhere by Davis JN, Spaniol MR (2015) who highlighted the potential of student's hands on during garden activities in enhancing their knowledge towards health eating and is in agreement with our study.

Contento et al. (2006) studied 115 second grade students and their knowledge, preference, and consumption of fruits and vegetables as part of a classroom and classroom/gardening program. The results indicated that participants who received nutrition education alone, as well as nutrition education and gardening education had increased nutrition knowledge and fruit/vegetable taste ratings than the control group.

Growing body of knowledge is providing evidence on positive effects of participation in "healthy school" over a short term (Keyte, etal.,,2012) and school gardens (Morgan et al., 2010) on health 14-year old in enhancing their knowledge over fruit and vegetable intake. However, Parmer et al., 2009 showed that a school garden intervention only significantly increases taste ratings rather than knowledge about nutritional value. The age level of learners used in Parmer's study were much young (second grade students) who could have been unable to comprehend the nutritional value of fruits and vegetables. This could have created the inconsistence in the findings.

Though he finding of Parmer et al., 2009 may not universally apply to the age group in our study (late adolescents), there was a strong relationship between students exposed to school gardening activities consuming fruits and vegetable $s$ because they were part of the school menu $(p<0.0001)$ not necessarily because of their richness in vitamins, fibres or minerals $(p>0.05)$.

This finding is consistent with the earlier findings by Ying et al., 2009 who reported gross lack of awareness, knowledge among adolescents regarding health eating. The adolescent have poorly developed frontal lobe which incapacitates their rational decisions (Ying et al., 2009). However, students 
can benefit from intake of fruits and vegetables because of an enabling school environment like through gardening even when they are not aware of the nutritional value of fruits and vegetables.

Students engaged in gardening activities in our study demonstrated positive attitude towards eating of fruits and vegetables. The exposed group to gardening activities had higher scores on the fruit and vegetable attitude questionnaire and they were able to appreciate that fruits taste good $(p=0.01108)$. This finding has been explained by (Robinson-O'Brien R, et al., 2009) who reported high attitude towards the intake of fruits and vegetables among the group exposed to gardening than the control.

Consequently, exposure to a wider range of vegetables and fruits through gardening activities has been observed to enhance a positive attitude (Kristjansdottir AG et al., 2006). Similarly involvement in the production and preparation of food can influence the attitude of the students towards intake of fruits and vegetables. Davis JN \& Spaniol MR (2015) reported that school gardens empower students by raising their attitude pertaining fruit and vegetable consumption. They also reported several fold increase in the self-motivation and a positive attitude towards intake of fruits and vegetables by adolescents engaged in gardening activities compared to the control. However, the study by Jaenke et al., (2012) reported no changes in fruit preference and vegetable intake as a result of a school gardening program.

The study was limited by scope as it was conducted in two schools only. These schools are both found in low social economic status settings. The results may differ in high social economic status settings where children have access to groceries and supermarkets with high quality and greater diversity of fruits and vegetables.

Both schools are mixed public schools under the universal secondary school program. This could have biased our findings

The questions in the survey commonly combined the fruits and vegetables for example how often do you eat fruits and vegetables? The responses may differ if two surveys were used; one for fruits only and another for vegetables. This could have caused discrepancies in our findings.

Again, clustering the fruits as for example hand fruits like bananas, apples, grapes could have biased the results because this could have reported a false frequency due to inclusion of bananas yet apples and grapes are rarely consumed by our participants.

In conclusion, the key findings of our study included the striking differences in frequency, knowledge, attitudes, self-efficacy towards fruit and vegetable intake across gender divide. 
Although adolescents involved in school gardening activities had higher weekly fruit and vegetable intake, overall, the intake of fruits among our study participants was low with servings per week less than the recommended serving by the United states Department of Agriculture, USDA.

The students in both settings knew the nutritional value of fruits and vegetables though the exposed students had higher scores. Moreover, the differences were not statistically significant.

The students had high self-efficacy and had self-confidence to eat fruits and vegetables in place of ice cream, a snack or three times a day attributable to gardening. There was a significant correlation between school gardening activities and consuming fruits and vegetables 3 times a day and, for a desert rather than the snack or ice cream.

The students in both settings had positive attitudes towards fruit and vegetable intake with the exposed group having higher scores. Thus hands on activity improve one's motivation to perform a nutritional behavioral response.

Study participants consumed more fruits than vegetables and had better knowledge, better attitude and high confidence in consuming fruits than vegetables.

The study was done among day students from low social economic status parents. So we recommended further studies in different settings to validate our findings.

The findings may differ if single sex, government or private schools were used, further studies can be done in such schools then compare with mixed schools or private schools were compared with government aided schools.

\section{Declarations}

\section{Ethics approval and consent to participate}

The study was conducted according to the guidelines laid down in the Declaration of Helsinki. The participants gave written informed consent to participate and withdraw from the study was voluntary. The research and ethics committee (REC) of Mild May Uganda approved the research project under the reference number of REC REF 0103-2019.

\section{Consent for publication}

The consent form had a section that requested participants to approve the publication of the findings of the study. Thus participants gave written informed consent to publish the report.

\section{Availability of data and material}

The datasets used and/or analyzed during the study are available from the corresponding author on reasonable request. 


\section{Competing interests}

The authors of the paper do not have any financial or personal relationship with the other people or organization that could inappropriately influence or bias the content of the paper. The authors therefore declare that they have no competing interests.

Funding

The work was funded by the faculty of Health Sciences Habib Medical School, Islamic university in Uganda.

\section{Author's contributions}

Hussein Mukasa Kafeero (HMK) contributed to the conceptions of the idea, design of the study, data analysis, drafting and writing of the manuscript. David Kavuma (DK) contributed to the design of the study and data analysis. The other authors; Lillian Nantume wampande (LNW) and Scovia Mbabazi (SM) made the final proof reading and editing.

\section{References}

World Health Organization, WHO: (2015). Adolescent health. Retrieved from http://www.who.int/topics/adolescent_health/en/

Arcan, C., Neumark-Sztainer, D., Hannan, P., van den Berg, P., Story, M., \& Larson, N. (2007). Parental eating behaviours, home food environment and adolescent intakes of fruits, vegetables, and dairy foods: Longitudinal finding from the project EAT. Public Health Nutrition, 10(11), 1257-1265. doi:10.1017/S1368980007687151

Bandura, A., 1986. Social foundations of thought and action: A social cognitive theory C. Englewood, ed., NJ: Prentice-Hall.

Behjat Shokrvash, (2013) Fruit and Vegetables Consumption among Adolescents: A Study from a Developing Country IDOSI Publications, DOI: 10.5829/idosi.wasj.2013.21.10.2920

Byron, E., Gillespie, S. \& Nangamib, M., 2006. Linking nutritional support with treatment of people living with HIV: lessons being learned in Kenya. Washington.

CDC 2015.. Youth risk behavioral surveillance system. Retrieved from Coleman-Jensen, A., Gregory, C. \& Singh, A. 2014. Household food security in the Unites Christian MS, El Evans C, Conner M, et al. (2012) Can a school gardening programme improve children's diets? BMC Public Health 12: 304. 
Contento, I.R., Manning, A.D. \& Shannon, B., 2006. "Research perspective on school-based nutrition education,." Journal of Nutrition Education, (24), pp.247-60.

Cockroft JE, Durkin M, Masding C \& Cade JE (2005) Fruit and vegetable intakes in a sample of pre-school children participating in the 'Five for All' project in Bradford. Public Health Nutr 8, 861-869.

Davis JN, Spaniol MR, S.S., 2015. Sustenance and sustainability: maximizing the impact of school gardens on health outcomes. Public Health Nutr., 18, pp.2358-67.

Di Noia, J., \& Byrd-Bredbenner, C. (2013). Adolescent fruit and vegetable intake: Influence of family support and moderation by home availability or relationships with afrocentric values and taste preferences. Journal of the Academy of Nutrition and Dietetics, 113, 803-808.

doi:10.1016/j.jand.2013.02.001

Faruque, A.S.. et al., 2008. Nutrition: Basis for healthy children and mothers in Bangladesh. Journal for health and population health, 26(3), pp.325-339.

Finkelstein, E. \& Strombotne, K., 2010. The economics of obesity. Am J Clin Nutr, 91(suppl), p.15201524.

Fitzgerald, A., Heary, C., Kelly, C., Nixon, E., \& Shevlin, M. (2013). Self-efficacy for healthy eating and peer support for unhealthy eating are associated with adolescents' food intake patterns. Appetite, 63, 48-58. doi:http://dx.doi.org/10.1016/j.appet.2012.12.011

Ganann, R. et al., 2014. Enhancing nutritional environments through access to fruit and vegetables in schools and homes among children and youth: A systematic review. BMC Research Notes, 7(1), pp.1-13.

Hagler, A. S.et al.,, 2005. Comparability and reliability of paper- and computer-based measures of psychosocial constructs for adolescent fruit and vegetables and dietary fat intake. Journal of the American Dietetic Association, 105, 1758-1764. doi:10.1016/j.jada.2005.08.010 http://mchb.hrsa.gov/programs/adolescents/.

Harrington EM, (2016). Fruit and Vegetable Intake, Attitudes, and Beliefs of Multicultural Middle School Students in Central Massachusetts Journal of the Academy of Nutrition and Dietetics, 113, 803-808

Heneman, K. et al., 2008. Pilot implementation of the improving children's health through farming, food, and fitness program in select California schools. Journal of Child Nutrition and Management, 32(1).

Kimmons, J., et al., 2009. Fruit and vegetable intake among adolescents and adults in the united states: Percentage meeting individualized recommendations. Medscape Journal of Medicine, 11(1), 26.

Keyte, J., Harris, S., Margetts, B., Robinson, S., \& Baird, J. (2012). Engagement with the National Healthy Schools Programme is associated with higher fruit and vegetable consumption in primary school 
children. Journal of Human Nutrition and Dietetics, 25(2), 155-160. https://doi.org/10.1111/j.1365277X.2011.01208.x

Jaenke RL, Collins CE, Morgan PJ, et al. (2012) The impact of a school garden and cooking program on boys' and girls' fruit and vegetable preferences, taste rating and intake. Health Education \& Behavior 39 : $131-141$

Khambalia, A. et al., 2012. A synthesis of existing systematic reviews and meta-analyses of school-based behavioural interventions for controlling and preventing obesity. Obes Rev, 13(3), pp.214-33.

Kim, S., A., Moore, L., V., Galuska, D., Wright, A., P., Harris, D., Grummer-Strawn, L., \&

Rhodes, D., G. (2014). Vital signs: Fruit and vegetable intake among children -

United States, 2003-2010. Morbidity \& Mortality Weekly Report, 63(31), 671-

676.

Kimani-Murage, E.W. et al., 2011. Predictors of adolescent weight status and central obesity in rural South Africa. . Public Health Nutr, 14, pp.1114-1122.

Kimokoti, R.. \& Hamer, D.H., 2008. Nutrition, health and aging in sub-Saharan Africa. Nutrition reviews, 66(11), pp.611-623.

Koch, S., Waliczek, T. \& Zajicek, J., 2006. The effect of a summer garden program on the nutritional knowledge, attitudes, and behaviors of children. HortTechnology, 16(4), pp.620-625.

Kothe EJ, Mullan BA and Butow P (2012) Promoting fruit and vegetable consumption. Testing an intervention based on the theory of planned behaviour. Appetite 58: 997-1004

Kristjansdottir AG, Thorsdottir I, De Bourdeaudhuij I, Due P, Wind M \& Klepp K-I (2006) Determinants of fruit and vegetable intake among 11-year-old schoolchildren in a country of traditionally low fruit and vegetable consumption. Int J Behav Nutr Phys Act 3, 41.

Krolner, R., Rasmussen, M., Brug, J., Knut-Inge, K., Marianne, W., \& Pernille, D. (2011). Determinant of fruit and vegetable consumption among children and adolescents: A review of the literature. Part II: Qualitative studies. International Journal of Behavioral Nutrition and Physical Activity, 8, 112. Retrieved from http://www.ijbnpa.org/content/8/1/112

Lasky, D. et al., 2002. Obesity and gender differences in the risk of type 2 diabetes mellitus in Uganda. Nutrition, 18, pp.417-421. 
Lineberger, S. \& Zajicek, J., 2000. School gardens: Can a hands-on teaching tool affect students' attitudes and behaviors regarding fruit and vegetables. Horticulture Technology, 10, pp.593-597.

Matt, G. E., Rock, C. L., \& Johnson-Kozlow, M. (2006). Using recall cues to improve measurement of dietary intakes with a food frequency questionnaire in an ethnically diverse population: An exploratory study. Journal of the American Dietetic Association, 106, 1209-1217. doi:10.1016/j.jada.2006.05.009

McAleese, J.D. \& Rankin, L.L., 2007. Garden-based nutrition education affects fruit and vegetable consumption in sixth-grade adolescents. Journal of the American Dietetic Association, 107, pp.662-665.

Mecacci, F. et al., 2015. Nutrition in pregnancy and lactation: how a healthy infant is born. Journal of pediatric and neonatal individualized medicine, 4(2), pp.1-14.

Molaison, E. et al., 2005. Influences on fruit and vegetable consumption by low-income black American adolescents. J Nutr Educ Behav, 37, pp.246-251.

Morgan PJ, Warren JM, Lubans DR, Saunders KL, Quick GI, Collins CE: The impact of nutrition education with and without a school garden on knowledge, vegetable intake and preferences and quality of school life among primary-school students. Public Health Nutr 2010, 13(11):1931-1940.

Neumark-Sztainer, D et.al, 2012. Secular trends in weight status and weight-related attitudes and behaviors in adolescents from 1999-2010. Preventive Medicine, 54,77-81.

Morris, J. \& Zidenberg-Cherr, S., 2002. Garden-enhanced curriculum improves fourth-grade school children's knowledge of nutrition and preferences for some vegetables. J Am Diet Assoc, 102, pp.91-93.

Neumark-Sztainer, D. et al., 2011. Dieting and disordered eating behaviors from adolescence to young adulthood: findings from a 10-year longitudinal study. J Am Diet Assoc, 111(7), pp.1004-11.

Nielsen, S.J., Rossen, L.M., Harris, D.M., Ogden, C.L. (2014). NCHS data brief no. 156. Fruit and vegetable consumption of U.S. youth, 2009-2010. Accessed via http://www.cdc.gov/nchs/data/databriefs/db156.htm\#source

Oxenham, E.; King, A.D., 2010. School Gardens as a Strategy for Increasing Fruit and Vegetable Consumption. Journal of Child Nutrition and Management., 4(1).

Parmer, S.M., Shannon, D (2009). School gardens: An experimental learning approach for nutritional education program to increase fruit and vegetable knowledge, preference, and consumption among second-grade students. J Nutr Educ Behav, 37, pp.246-251. 
Peltzer, K.; Pengpid, S. 2010. Fruits and vegetables consumption and associated factors among in school adolescents in seven African countries. Int. J. Public Health 2010, 55, 669-678.

position paper of the society for adolescent medicine. Journal of Adolescent Health, 17, 270-

Pedersen, S., Grønhøj, A., \& Thøgersen, J. (2015). Following family or friends. Social norms in adolescent healthy eating. Appetite, 86, 54-60.

Popkin, B., 2006. Global nutrition dynamics: the world is shifting rapidly toward a diet linked with noncommunicable diseases. Am J Clin Nutr, 84, pp.289-298.

Popkin, B.M., Adair, L.S. \& Ng, S.W., 2012. Global nutrition transition and the pandemic of obesity in developing countries. Nutr. Rev, 70, pp.3-21.

Robinson-O'Brien, R., Story, M. \& Heim, S., 2009. Impact of garden-based youth nutrition intervention programs: A review. Journal of the American Dietetic Association, 109, pp.273-280.

Rockett, H.R.H., Wolf, A.M., \& Colditz, G.A. 1995. Development and reproducibility of a

Somerset, S. \& Markwell, K., 2009. Impact of a school-based food garden on attitudes and identification skills regarding vegetables and fruit: a 12-month intervention trial. Public Health Nutr, 12, pp.214-21.

Sharma, S., Sheehy, T., \& Kolonel, L. 2014). Sources of vegetables, fruits and vitamins A, C and E among five ethnic groups: Results from a multiethnic cohort study. European Journal of Clinical Nutrition, 68, 384-391.

Society of Adolescent Medicine (SAM) 1995. Guidelines for adolescent health research: A

States in 2013. A report summary from the Economic Research Service. USDA. Retrieved May 24, 2015 from http://www.ers.usda.gov/media/1565410/err173_summary.pdf

Steinberg, L. (2014). Age of opportunity: Lessons from the new science of adolescence. Boston,

Sylvetsky, A. C., Hennink, M., Comeau, D., Welsch, J. A., Hardy, T., Matzigkeit, L., . . Vos, B. (2013). Youth understanding of healthy eating and obesity: A focus group study. Journal of Obesity. Retrieved from http://downloads.hindawi.com/journals/jobes/2013/670295.pdf

Thompson, V. J et al., 2007. Self-efficacy and norm measures for lunch fruit and vegetable consumption are reliable and valid among fifth grade students. Journal of Nutrition Education and Behavior, 39(1), 2-7. 
Turi, K.N., Christoph, M.J. \& Grigsby-Toussaint, D.S., 2013. Spatial distribution of underweight, overweight and obesity among women and children: Results from the 2011 Uganda demographic and health survey. International Journal of Environmental Research and Public Health, 10(10), pp.4967-4981.

U.S. Department of Agriculture, Economic Research Service. (2015). [Interactive graphic illustration of food access in America, May 13, 2015]. Food Access Research Atlas. Retrieved from http://www.ers.usda.gov/data-products/food-accessresearch- atlas/go-to-the-atlas.aspx

Ying-Ying Goh, Bogart, L., Sipple-Asher, B., Uyeda, K., Hawes-Dawson, J., Olarita- Dhungana, J., . . . Schuster, M. (2009). Using community-based participatory research to identify potential interventions to overcome barriers to adolescents' healthy eating and physical activity. Journal of Behavioral Medicine,32(5), 491- 502. doi:10.1007/s10865-009-9220-9

\section{Tables}

Table 1: Demographic characteristics for the exposed and un exposed school to gardening practice

\begin{tabular}{llll}
\hline Characteristic & unexposed & Exposed & Total \\
\hline Sample size, $\mathrm{n}$ & 170 & 185 & 355 \\
\hline Gender, & & & \\
\hline Boys, $\mathrm{n}(\%)$ & $93(54.7)$ & $107(57.8)$ & $200(56.3)$ \\
\hline Girls, $\mathrm{n}(\%)$ & $77(45.3)$ & $78(42.2)$ & $155(43.7)$ \\
\hline Age, Mean \pm SD & & & \\
\hline Boys & $19.11 \pm 1.29$ & $19.2 \pm 2.86$ & \\
\hline Girls & $18.62 \pm 1.21$ & $19.10 \pm 1.4$ & \\
\hline
\end{tabular}

Table 2: Distribution of fruit and vegetable intake of students per week in the exposed and unexposed schools 


\begin{tabular}{lcc}
\hline Type of fruit/Vegetable & $\begin{array}{c}\text { Unexposed school (185) } \\
\text { Mean } \pm \text { SD }\end{array}$ & $\begin{array}{c}\text { Exposed school (185) } \\
\text { Mean } \pm \text { SD }\end{array}$ \\
\hline Vegetable salad intake & $4.32 \pm 6.67$ & $3.8 \pm 3.7$ \\
\hline Cooked/steamed greens & $3.62 \pm 3.68$ & $4.2 \pm 4.0$ \\
\hline Raw vegetables like cucumber & $6.01 \pm 2.72$ & $7.4 \pm 7.7$ \\
Beans & $11.09 \pm 10.0$ & $11.6 \pm 11$ \\
\hline
\end{tabular}

\section{Average vegetable weekly intake}

$6.5 \pm 6.14$

Tropical fruits like guava, mango, pineapple

Hand fruits like bananas, apples, grapes

$6.26 \pm 5.67$

$6.65 \pm 6.6$

Avocados

Melon

(1)

\begin{tabular}{cc}
\hline $6.55 \pm 7.804$ & $7.2 \pm 8.9$ \\
$5.88 \pm 6.19$ & $6.5 \pm 7.2$ \\
$10.28 \pm 10.69$ & $12.3 \pm 10$ \\
\hline $9.994 \pm 9.86$ & $9.1 \pm 7.8$ \\
\hline $\mathbf{8 . 2} \pm \mathbf{8 . 6}$ & $\mathbf{8 . 8} \pm \mathbf{8 . 5}$
\end{tabular}

Average fruit weekly intake

$8.5 \pm 8.6$

Table 3: The $2 \times 2$ table showing the distribution of weekly fruit and vegetable intake among the unexposed and exposed students to gardening activities

\begin{tabular}{lllllll}
\hline & Fruit intake & Vegetable intake & Total & OR & P-value & 95\%CI \\
\hline Unexposed & 8 & 6 & 14 & & & \\
Exposed & 9 & 7 & 16 & & & \\
\hline Total & 17 & 13 & 30 & 1.037 & 0.9607 & 0.2267 to 4.1018 \\
\hline
\end{tabular}

Table 4: Mean scores \pm SD on the attitudes towards fruit and vegetable intake among the students exposed and unexposed to gardening activities

\begin{tabular}{lccc}
\hline Student's attitude & Unexposed School $(\mathrm{n}=170)$ & Exposed school $(\mathrm{n}=185)$ & P-value \\
\cline { 2 - 3 } & Mean frequency Score \pm SD & Mean score \pm SD & \\
\cline { 2 - 3 } Fruits taste good & $3.3 \pm 0.7$ & $3.7 \pm 0.6$ & $\mathbf{0 . 0 1 1 0 8}$ \\
\hline Vegetables taste good & $3.2 \pm .041$ & $3.5 \pm 0.4$ & 0.67448 \\
\hline Peers too eat fruits \& vegetables & $0.9 \pm 1.0$ & $0.8 \pm 1.0$ & 0.4777 \\
\hline Fruits and vegetables are bitter/sour & $1.6 \pm 1.3$ & $1.7 \pm 1.5$ & 0.41222 \\
\hline Total Mean score & $2.25 \pm 0.9$ & $2.43 \pm 0.9$ & \\
\hline \hline
\end{tabular}

Table 5: Mean frequency scores (\%) on the attitudes towards fruit and vegetable intake among the students exposed and unexposed to gardening activities 


\begin{tabular}{lcc}
\hline Student's attitude & Unexposed school $(\mathrm{n}=170)$ & Exposed $(\mathrm{n}=185)$ \\
\cline { 2 - 3 } & Mean frequency $(\%)$ & Mean frequency (\%) \\
\hline Fruits taste good & $3.3(82.5)$ & $3.7(92.5)$ \\
\hline Vegetables taste good & $3.2(80.0)$ & $3.5(87.5)$ \\
\hline Peers too eat fruits \& vegetables & $0.9(22.5)$ & $0.8(20.0)$ \\
\hline Fruits and vegetables are bitter/sour & $1.6(40)$ & $1.7(42.5)$ \\
\hline Total mean frequency & $2.25(56.3)$ & $2.43(60.6)$ \\
\hline \hline
\end{tabular}

Table 6: Mean scores for the students attitudes towards vegetable intake for the exposed and unexposed to gardening activities

\begin{tabular}{|c|c|c|c|c|}
\hline Unexposed $(n=170)$ & Exposed $(n=185)$ & t-score & p-value & $95 \% \mathrm{CI}$ \\
\hline Mean \pm SD & Mean \pm SD & & & \\
\hline $1.671 \pm 0.7115$ & $2.136 \pm 0.6347$ & 6.53 & $\mathrm{p}<0.0001$ & 0.325 to 0.606 \\
\hline
\end{tabular}

Table 7: Mean score for the students attitudes towards intake of fruits in the among the exposed and unexposed groups

\begin{tabular}{lllll}
\hline & Mean \pm SD & t-value & p-value & 95\%CI \\
\hline Exposed $(\mathrm{n}=185)$ & $2.26 \pm 0.619$ & & & \\
\hline Unexposed $(\mathrm{n}=170)$ & $1.78 \pm 0.712$ & -10.325 & $\mathrm{p}<0.0001$ & -0.8122 to -0.5518 \\
\hline
\end{tabular}

Table 8: Mean scores and \% of the total scores for student's knowledge on fruit and vegetable intake among the exposed and the unexposed students to gardening activities

\begin{tabular}{lccc}
\hline Student's knowledge & Unexposed $(\mathrm{n}=170)$ & Exposed $(\mathrm{n}=185)$ & p-value \\
\cline { 2 - 3 } & Mean score & Mean score & \\
\hline Eating fruits is important for health & $3.3 \pm 0.7$ & $3.5 \pm 0.6$ & 0.01108 \\
Fruits are sources of vitamins & $3.6 \pm 0.6$ & $3.5 \pm 0.7$ & 0.13104 \\
\hline Fruits are served on school menu & $0.4 \pm 0.7$ & $3.4 \pm 1.0$ & $<0.00001$ \\
\hline Total mean score & $7.3 \pm 2.0$ & $10.4 \pm 2.3$ & \\
\hline Vegetables are good for health & $3.6 \pm .041$ & $3.8 \pm 0.4$ & 0.67448 \\
\hline Vegetables are dietary fibers & $2.9 \pm 1.1$ & $2.8 \pm 1.0$ & 0.58232 \\
\hline Vegetables are rich in minerals & $2.9 \pm 1.2$ & $3.0 \pm 1.2$ & 0.8966 \\
\hline Total Mean score & $6.1 \pm 2.71$ & $10.1 \pm 2.6$ & \\
\hline
\end{tabular}


Table 9: The 2x2 table on the student's knowledge as regards the nutritional value of fruits and vegetables among the exposed and unexposed students to gardening activities

\begin{tabular}{lllllll}
\hline & Fruit intake & Vegetable intake & Total & OR & p-value & 95\%CI \\
\hline Unexposed & 7 & 6 & 13 & & & \\
Exposed & 11 & 10 & 21 & & & \\
\hline Total & 18 & 16 & 34 & 1.06 & 0.876 & 1.44 to -1.32 \\
\hline
\end{tabular}

Table 10: Mean self-efficacy scores for fruit and vegetable intake among the exposed and the unexposed students to gardening activities

\begin{tabular}{lccc}
\hline & Unexposed $(\mathrm{n}=170)$ & Expose $(\mathrm{n}=185)$ & P-value \\
\cline { 2 - 3 } & Mean $\pm \mathrm{SD}$ & Mean $\pm \mathrm{SD}$ & \\
\hline I can eat a F/V instead of chips as a snack & $3.01 \pm 1.18$ & $5.58 \pm 1.31$ & 0.00804 \\
\hline I can eat a F/V instead of ice-cream as a desert & $2.82 \pm 1.35$ & $3.64 \pm 1.48$ & 0.0042 \\
\hline I can eat a F/V 3 times a day & $2.60 \pm 1.14$ & $3.67 \pm 2.60$ & $<0.00001$ \\
\hline I am sure I can eat F \& V every breakfast & $3.17 \pm 1.55$ & $3.90 \pm 1.09$ & 0.00338 \\
\hline I am sure I can eat F \& V every lunch & $3.19 \pm 1.79$ & $3.81 \pm 1.42$ & 0.05118 \\
\hline I am sure I can eat F \& V every dinner & $3.45 \pm 1.46$ & $3.85 \pm 1.46$ & 0.06724 \\
\hline I can eat a F/V 2 times a day & $3.43 \pm 1.52$ & $3.09 \pm 1.37$ & 0.1074 \\
\hline
\end{tabular}

Table 11: Correlation between self-efficacy scores to fruit and vegetable intake attributable to gardening activities

\begin{tabular}{|c|c|c|c|}
\hline Gardening activities & $\begin{array}{l}\text { I can eat fruits and } \\
\text { vegetables rather a chip as a } \\
\text { snack }\end{array}$ & $\begin{array}{c}\text { I can eat Fruits and } \\
\text { Vegetables 3times a } \\
\text { day }\end{array}$ & $\begin{array}{c}\text { I can eat fruits and } \\
\text { vegetables every } \\
\text { dinner }\end{array}$ \\
\hline \multirow[t]{3}{*}{$\begin{array}{l}\text { We grow fruits } \& \\
\text { vegetables at school }\end{array}$} & $\mathrm{R}=0.15$ & $\mathrm{R}=0.21$ & $\mathrm{R}=0.205$ \\
\hline & $\mathrm{R} 2=0.0214$ & $\mathrm{R}^{2}=0.044$ & $\mathrm{R} 2=0.042$ \\
\hline & $\mathrm{P}=0.04776$ & $\mathrm{p}=0.004399$ & $\mathrm{p}=0.005223$ \\
\hline \multicolumn{4}{|l|}{ I am involved in gardening } \\
\hline & $\mathrm{R}=0.1559$ & $\mathrm{R}=0.1935$ & $\mathrm{R}=0.1335$ \\
\hline & $\mathrm{R}^{2}=0.0243$ & $\mathrm{R}^{2}=0.0374$ & $\mathrm{R} 2=0.0178$ \\
\hline & $\mathrm{p}=0.034084$ & $\mathrm{p}=0.008314$ & $\mathrm{p}=0.070047$ \\
\hline \multirow{4}{*}{$\begin{array}{l}\text { My desired fruits are } \\
\text { present in the school } \\
\text { garden }\end{array}$} & & & \\
\hline & $\mathrm{R}=0.174$ & $\mathrm{R}=0.2057$ & $\mathrm{R}=0.1632$ \\
\hline & $\mathrm{R}^{2}=0.0303$ & $\mathrm{R}^{2}=0.0423$ & $\mathrm{R} 2=0.0266$ \\
\hline & $\mathrm{P}=0.01785$ & $\mathrm{p}=0.005123$ & $p=0.026445$ \\
\hline
\end{tabular}


Figures

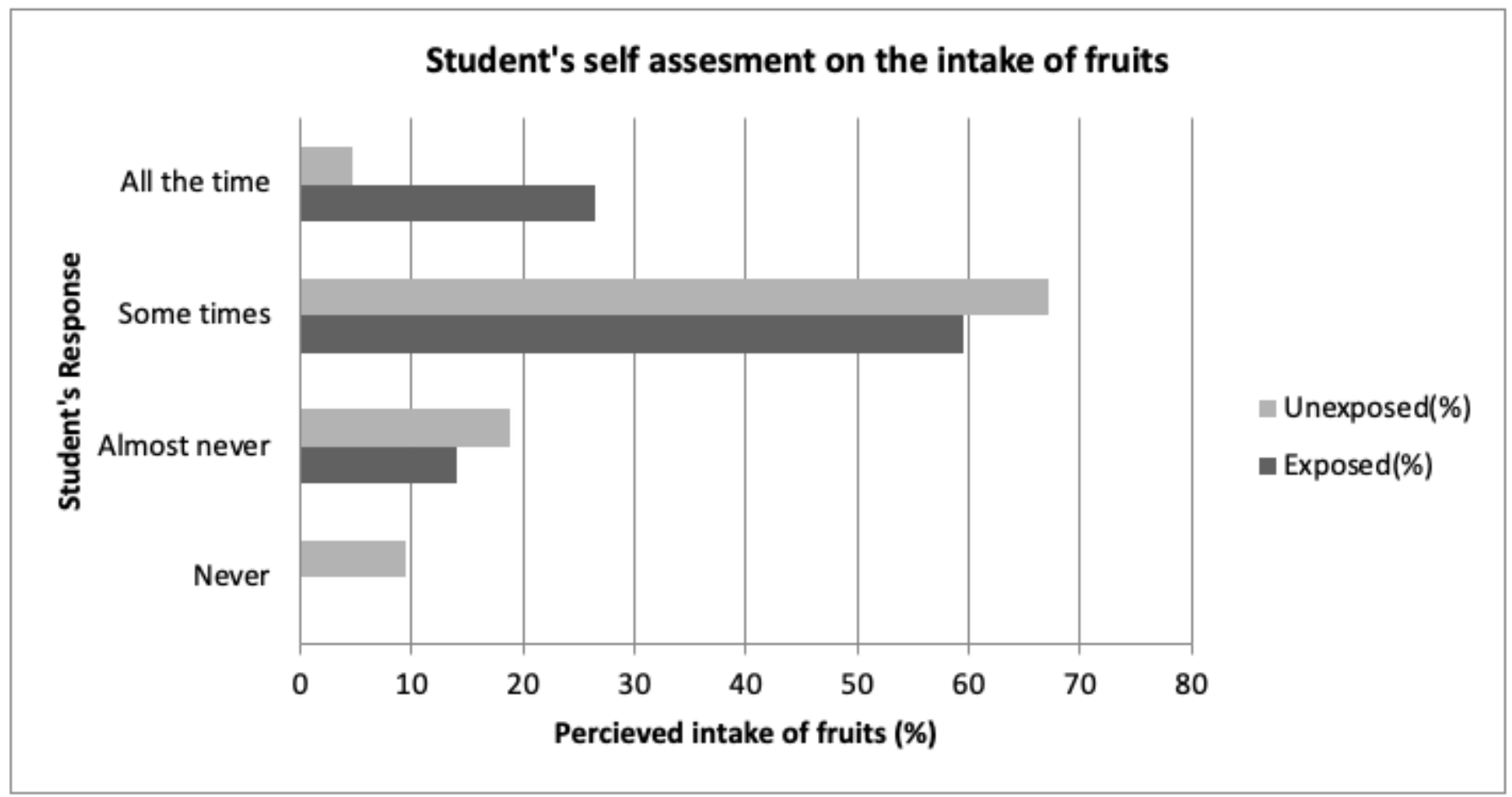

Figure 1

Distribution of perceived intake of fruits among the exposed and unexposed students. 


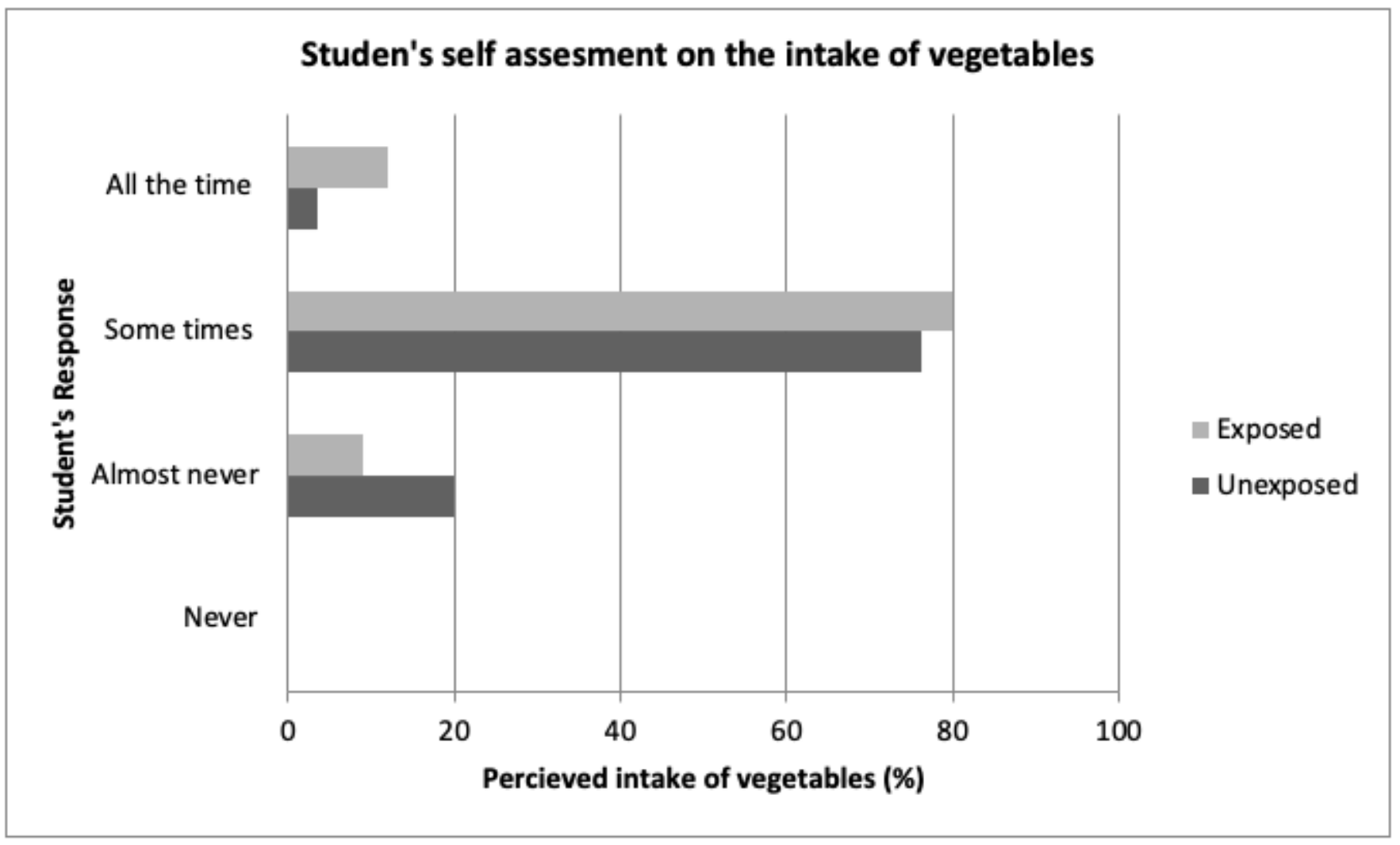

Figure 2

Distribution of perceived intake of vegetables among the exposed and un exposed students. 